\title{
SISTEM INFORMASI LABORATORIUM BERBASIS WEBSITE DI PROGRAM STUDI D IV TEKNIK INFORMATIKA POLITEKNIK HARAPAN BERSAMA TEGAL
}

\author{
M. Nishom*, Dega Surono Wibowo \\ Program Studi D IV Teknik Informatika, Politeknik Harapan Bersama \\ Jl. Mataram No.9 Pesurungan Lor, Margadana, Kota Tegal, Indonesia 52147 \\ Email: nishom@poltektegal.ac.id
}

\begin{abstract}
Laboratory is one of the important components in a college, where scientific research, experimentation, development or scientific training activities and even teaching-learning activities are carried out in it, so that a good schedule of space usage management and information on the availability of equipment is needed to support the smooth operation of laboratory use. At present, the process of laboratory services in the Informatics Engineering department of Politeknik Harapan Bersama is still carried out in a conventional manner, where all spatial use activities are recorded in a book, making it ineffective and less efficient. This study aims to build a Laboratory Information System in the Informatics Engineering Department of Politeknik Harapan Bersama. Data collection was performed using the triangulation method. StarUML was chosen as a tool for modeling UML-based systems, and blackbox as a method for testing system functionality. The results of this study are Web-based Laboratory Information Systems. It is expected that with this information system, it can further improve the service and effectiveness of the use of laboratories in the Informatics Engineering Department.
\end{abstract}

Keywords: information systems; web-based apps; laboratory; uml; blackbox

\section{PENDAHULUAN}

Kualitas atau mutu merupakan sebuah nilai yang tidak perlu dipertanyakan lagi bagi sebuah organisasi, terutama institusi perguruan tinggi. Keberhasilan suatu perguruan tinggi tidak hanya dilihat dari satu faktor saja, tetapi banyak faktor yang menentukan keberhasilan tersebut. Baik itu faktor eksternal (seperti hubungan perguruan tinggi dengan masyarakat, perguruan tinggi dengan pemerintah, dan lain sebagainya) maupun faktor internal. Salah satu faktor internal yang perlu diperhatikan adalah kualitas manajemen yang baik dan pelayanan yang memuaskan dengan mengoptimalkan sesuatu yang bersifat operasional dalam perguruan tinggi, salah satunya adalah manajemen penggunaan Laboratorium menggunakan sistem informasi. Sistem informasi dipilih karena merupakan kombinasi teratur dari orang-orang hardware, software, jaringan komunikasi dan sumber daya data yang mengumpulkan, mengubah, dan menyebarkan informasi dalam sebuah organisasi [1], [2], [3]. Sistem informasi juga merupakan kombinasi perangkat keras, perangkat lunak, infrastruktur, dan personel terlatih yang diorganisasikan untuk memfasilitasi perencanaan, pengendalian, koordinasi, dan pengambilan keputusan dalam suatu organisasi [4].

Laboratorium merupakan bagian yang tidak dapat dipisahkan dalam suatu perguruan tinggi, karena dapat membantu dalam kelancaran kegiatan perkuliahan, penelitian dan pengembangan, terlebih bagi Politeknik Harapan Bersama Tegal mempunyai beberapa program studi yang di dalam perkuliahannya masih banyak menggunakan laboratorium. Saat ini, proses belajar mengajar di program studi Teknik Informatika Politeknik Harapan Bersama Tegal sebagian besar masih dilakukan di dalam ruangan laboratorium. Selain itu, beberapa kegiatan (seperti kegiatan penelitian, pengembangan, pelatihan, belajar mandiri mahasiswa, kegiatan akademik, kegiatan unit/divisi perguruan tinggi, dan bahkan kegiatan perguruan tinggi) juga terkadang memanfaatkan ruangan tersebut, sehingga diperlukan manajemen jadwal ruangan yang baik agar dapat memberikan informasi dan pelayanan yang memuaskan pada stakeholder.

Permasalahan yang muncul adalah belum dimilikinya sistem yang terintegrasi untuk dapat melihat informasi jadwal penggunaan ruang laboratorium, sistem peminjaman ruang laboratorium, dan event yang diselenggarakan di laboratorium, misalnya adalah lomba dan peminjaman laboratorium oleh mahasiswa, dosen, program studi lain, maupun unit kerja di Politeknik Harapan Bersama tegal. Petugas lab dalam hal ini laboran dan koordinator lab hanya akan mencatat dan mengarsipkan segala macam kegiatan dalam map atau jurnal kegiatan, serta jika ada peminjaman laboratorium harus melakukan koordinasi dengan koordinator laboratorium, dan melihat list penggunaan laboratorium hanya pada dokumen spreadsheet jadwal penggunaan laboratorium. Tentunya hal ini sangat tidak efektif dan tidak efisien.

Dengan demikian diperlukan adanya sistem informasi sebagai solusi, karena keberadaan sistem informasi dalam sebuah organisasi dapat membantu organisasi dalam berbagai aspek seperti meningkatkan efisiensi dan efektivitas proses bisnis, 
pengambilan keputusan, meningkatkan produktivitas organisasi dan memberikan keunggulan yang kompetitif [5]. Selain keberadaan sistem informasi, kemudahan dalam mengakses sistem informasi dan efektivitas serta efisiensi juga merupakan aspek yang perlu diperhitungkan, agar dapat menunjang pekerjaan jajaran manajerial dalam memberikan disposisi, unit bidang dalam membuat pelaporan, sehingga dapat memberikan kepuasan pada stakeholder dengan pelayanan yang cepat. Sistem informasi berbasis web merupakan sistem informasi paling tepat untuk digunakan sebagai solusi, karena dapat berjalan di internet, intranet atau ekstranet perusahaan [6], sehingga mudah diakses kapan saja dan di mana saja selama tersambung dengan internet.

Beberapa penelitian serupa dan terkait penggunaan ruang dan alat, dan penjadwalan laboratorium telah dilakukan oleh para peneliti sebelumnya, diantaranya pembangunan sebuah Analisis Dan Perancangan Sistem Informasi Manajemen Laboratorium STMIK STIKOM Bali Berbasis Web [7], sesuai dengan judulnya perancangan aplikasi atau sistem yang dibuat adalah berbasis website, sedangkan analisis dilakukan dengan menggunakan pendekatan pieces, dalam perancangan sistemnya digunakan model proses DFD (Data Flow Diagram) untuk menggambarkan model fungsi atau proses fungsionalitasnya. Penelitian serupa lainnya berjudul Aplikasi Peminjaman Ruangan, Kendaraan, Peralatan di Uppk Universitas Kristen Petra [8], dalam penelitian tersebut aplikasi dikembangkan dengan menggunakan native-PHP dan database yang digunakan adalah MySQL, sedangkan model proses yang digunakan dalam perancangan sistem adalah model proses DFD. Penelitian terkait lainnya adalah sebuah peelitian dengan judul Sistem Informasi Laboratorium Komputer di Universitas Nusantara PGRI Kediri [9], sistem yang dikembangkan masih menggunakan native-PHP programming (atau belum menggunakan framework) serta belum menggunakan web-template, sehingga user interface atau tampilan aplikasi tidak responsive. Sistem Informasi Jadwal Perkuliahan Berbasis Web Mobile Pada Politeknik Sains dan Teknologi Wiratama Maluku Utara [10], Sistem Penjadwalan kuliah di STMIK AUB Surakarta [11] merupakan penelitian serupa yang dikembangkan untuk manajemen jadwal penggunaan ruang dan jadwal perkuliahan dengan bahasa pemrograman native-PHP dan tidak menggunakan framework. Penelitian serupa dan terkait lainnya adalah penelitian dengan judul Sistem Informasi Maintenance Dan Inventaris Laboratorium di SMK Negeri 1 Rembang [12] yang dikembangkan berbasis web dengan native-PHP dan menggunakan UML (Unified Modeling Language) dalam pemodelan sistemnya, tetapi sayangnya masih belum menggunakan framework maupun webtemplate sehingga user-interface yang dihasilkan tidak responsive. Namun demikian, kondisi di laboratorium Program Studi D IV Teknik Informatika
Politeknik Harapan Bersama Tegal memiliki "kebutuhan khusus" dan tidak dapat diatasi menggunakan sistem yang sudah dikembangkan dalam penelitian sebelumnya tersebut, sehingga dalam penelitian ini dibangun sebuah sistem informasi pelayanan laboratorium berbasis website untuk membantu manajemen laboratorium Program Studi Teknik Informtika Politeknik Harapan Bersama dalam mengelola jadwal penggunaan ruang, manajemen alat, serta manajemen pelaporan untuk memberikan pelayanan prima kepada stakeholder. Pengembangan sistem dalam penelitian ini menggunakan framework CodeIgniter untuk menunjang proses pengembangan sistem agar dapat dilakukan dengan cepat (namun memiliki tingkat keamanan yang cukup), dan pemodelan sistem dilakukan menggunakan pendekatan UML yang bersifat Object Oriented Design, dan metode blackbox untuk pengujian sistem

\section{METODE PENELITIAN}

Untuk menjamin kelancaran setiap proses penelitian, dalam penelitian ini digunakan sebuah kerangka penelitian (dapat dilihat pada Gambar 1). Bahan yang digunakan dalam penelitian ini meliputi: data ruang laboratorium; data laboran; data admin program studi; data dosen; data mahasiswa dan data unit/divisi di Politeknik Harapan Bersama Tegal. Selain perangkat keras, dukungan perangkat lunak (software) juga diperlukan dalam melakukan perancangan dan implementasi program diantaranya: Apache Netbeans IDE (tools untuk pembuatan dan pengembangan software); CodeIgniter 3.x (framework PHP); StarUML (Software untuk desain dan perancangan sistem); Browser (Firefox, Chrome, dan MS Edge) untuk pengujian UI/UX sistem; Paket aplikasi XAMPP (paket aplikasi sebagai server lokal); dan Sublime Text sebagai Code Editor. Metode pengembangan sistem yang digunakan dalam penelitian ini adalah Rapid Application Development (RAD), metode ini dipilih karena paling banyak digunakan dalam pengembangan sistem [13] dan paling cocok untuk pengembangan sistem dalam waktu yang cepat. Alur pengembangan sistem menggunakan metode RAD seperti terlihat pada Gambar 2.

Pengumpulan Data: Metode pengumpulan data yang digunakan dalam penelitian ini adalah metode triangulasi. Metode ini merupakan metode yang menggabungkan bebeapa teknik pengumpulan data dan sumber data yang telah ada [14]. Pengumpulan data dimulai dengan wawancara dan mengamati secara langsung (observasi) terhadap kondisi pelayanan dan manajemen pada di laboratorium program studi Teknik Informatika Politeknik Harapan Bersama Tegal. Selanjutnya, pengumpulan data dilanjutkan dengan meminta data yang dibutuhkan dalam penelitian ke Program Studi Teknik Informatika Politeknik Harapan Bersama Tegal. Adapun data yang telah diambil meliputi: Data 
ruang laboratorium; Data laboran; Data admin program studi; Data dosen; Data Mahasiswa; dan data unit/divisi di Politeknik Harapan Bersama Tegal.

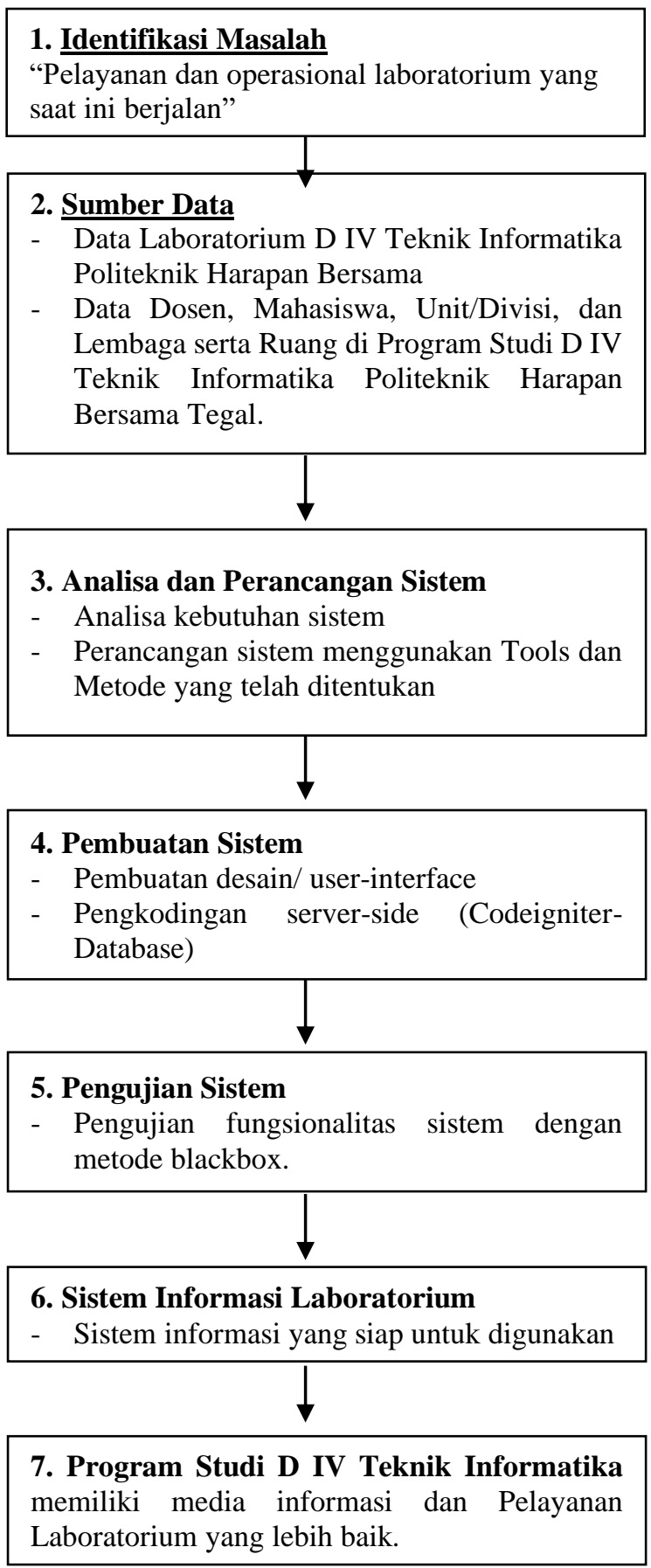

Gambar 1. Kerangka Penelitian

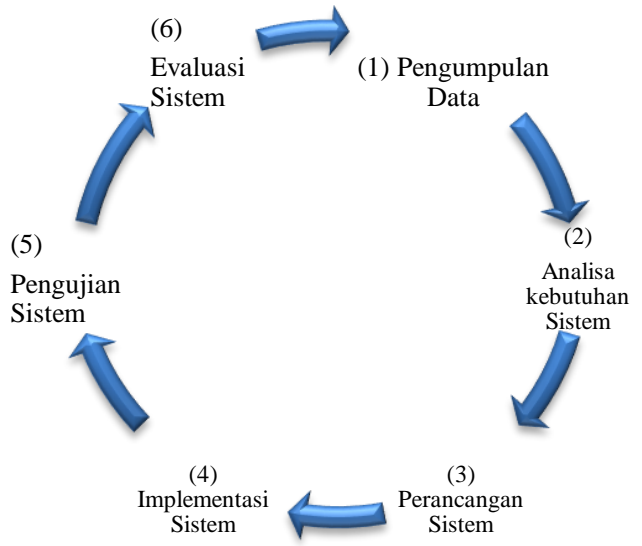

Gambar 2. Alur Pengembangan Sistem menggunakan metode Rapid Application Development

Analisa Kebutuhan Sistem: Analisis dilakukan dengan melakukan identifikasi terhadap kebutuhan fungsional (dapat lihat pada Tabel 1) dan non-fungsional (dapat dilihat pada Tabel 2) sistem. Kebutuhan fungsional adalah kebutuhan pada sistem yang merupakan layanan dalam aplikasi yang harus disediakan. Kebutuhan fungsional yang telah dianalisis ditunjukkan pada Tabel 1 dan Tabel 2.

Tabel 1. Kebutuhan Fungsional

\begin{tabular}{|c|c|}
\hline Pengguna & Kebutuhan \\
\hline $\begin{array}{l}\text { Koordinator } \\
\text { Laboratoriu } \\
\mathrm{m}\end{array}$ & $\begin{array}{l}\text { a) Dapat mengelola data ruang } \\
\text { b) Dapat mengelola data alat } \\
\text { c) Dapat mengelola permintaan } \\
\text { dan penerimaan barang/alat } \\
\text { d) Dapat mengelola data master } \\
\text { e) Memberikan disposisi } \\
\text { f) Melihat laporan } \\
\text { g) Pengaturan Sistem } \\
\text { h) Merubah/mereset password }\end{array}$ \\
\hline Pengguna & Kebutuhan \\
\hline Laboran & $\begin{array}{l}\text { a) Dapat mengelola jadwal } \\
\text { penggunaan } \\
\text { laboratorium } \\
\text { b) Dapat mengelola permintaan } \\
\text { peminjaman ruang dan alat } \\
\text { c) Melihat riwayat peminjaman } \\
\text { alat } \\
\text { d) Merubah dan mereset } \\
\text { password } \\
\text { e) Melihat laoran kerusakan atau } \\
\text { disfungsi barang } \\
\text { (alat/komputer) }\end{array}$ \\
\hline Mahasiswa & $\begin{array}{l}\text { a) Melihat informasi dan jadwal } \\
\text { atau ketersediaan ruang/alat } \\
\text { b) Dapat meminjam ruang/alat }\end{array}$ \\
\hline Other & $\begin{array}{l}\text { a) Meminjam ruang/alat } \\
\text { b) Melihat riwayat peminjaman } \\
\text { c) Merubah/mereset password }\end{array}$ \\
\hline
\end{tabular}


(UPT/

Lembaga/

Dosen)

Tabel 2. Kebutuhan non-Fungsional

\begin{tabular}{|c|c|}
\hline Kategori & Kebutuhan \\
\hline $\begin{array}{l}\text { Perangka } \\
\text { t Keras }\end{array}$ & $\begin{array}{ll}\text { Laptop Lenovo B480: spesifikasi } \\
\text { - } & \text { RAM 6GB (minimum) } \\
\text { - } & \text { Mainboard Intel } \\
\text { - } & \text { Processor Intel }{ }^{\circledR} \text { Core TM i3- } \\
& \text { 2330M CPU @ 2.20GHz (4 } \\
& \text { CPUs) } \\
\text { - } & \text { Display: Intel @ HD Graphic } \\
& \text { 3000 dengan resolusi 1366x768 } \\
\text { - } & \text { Harddisk: 500GB }\end{array}$ \\
\hline \multirow[t]{2}{*}{$\begin{array}{l}\text { Perangka } \\
\text { t Lunak }\end{array}$} & $\begin{array}{l}\text { a) Sistem Operasi Windows } 10 \text { Pro } \\
\text { b) Star UML 3.1.0, sebagai alat } \\
\text { untuk melakukan perancangan } \\
\text { dan pemodelan sistem berbasis } \\
\text { object-oriented. }\end{array}$ \\
\hline & $\begin{array}{l}\text { c) Apache Netbeans IDE } 11.1, \\
\text { sebagai } \\
\text { pembangunan sistem. }\end{array}$ \\
\hline
\end{tabular}

d) XAMPP 7.1.7: Paket Software

- Database Server: MySQL (10.1.25-MariaDB).

- Web Server: Apache/2.4.26

(Win32)

PHP/7.1.7.

- phpMyAdmin 4.7.0, sebagai alat untuk mengelola basis data.

e) Codeigniter 3.x, sebagai framework untuk memudahkan dalam pembuatan/pembangunan sistem.

f) Sublime Text 3.x, sebagai teks/kode editor.

g) Browser (Chrome, Firefox, Internet Explorer): sebagai media untuk menampilkan halamanhalaman sistem/ aplikasi.

Perancangan Sistem: Pertama, dilakukan perancangan database dan fungsionalitas sistem menggunakan use case diagram seperti yang terlihat pada Gambar 3.

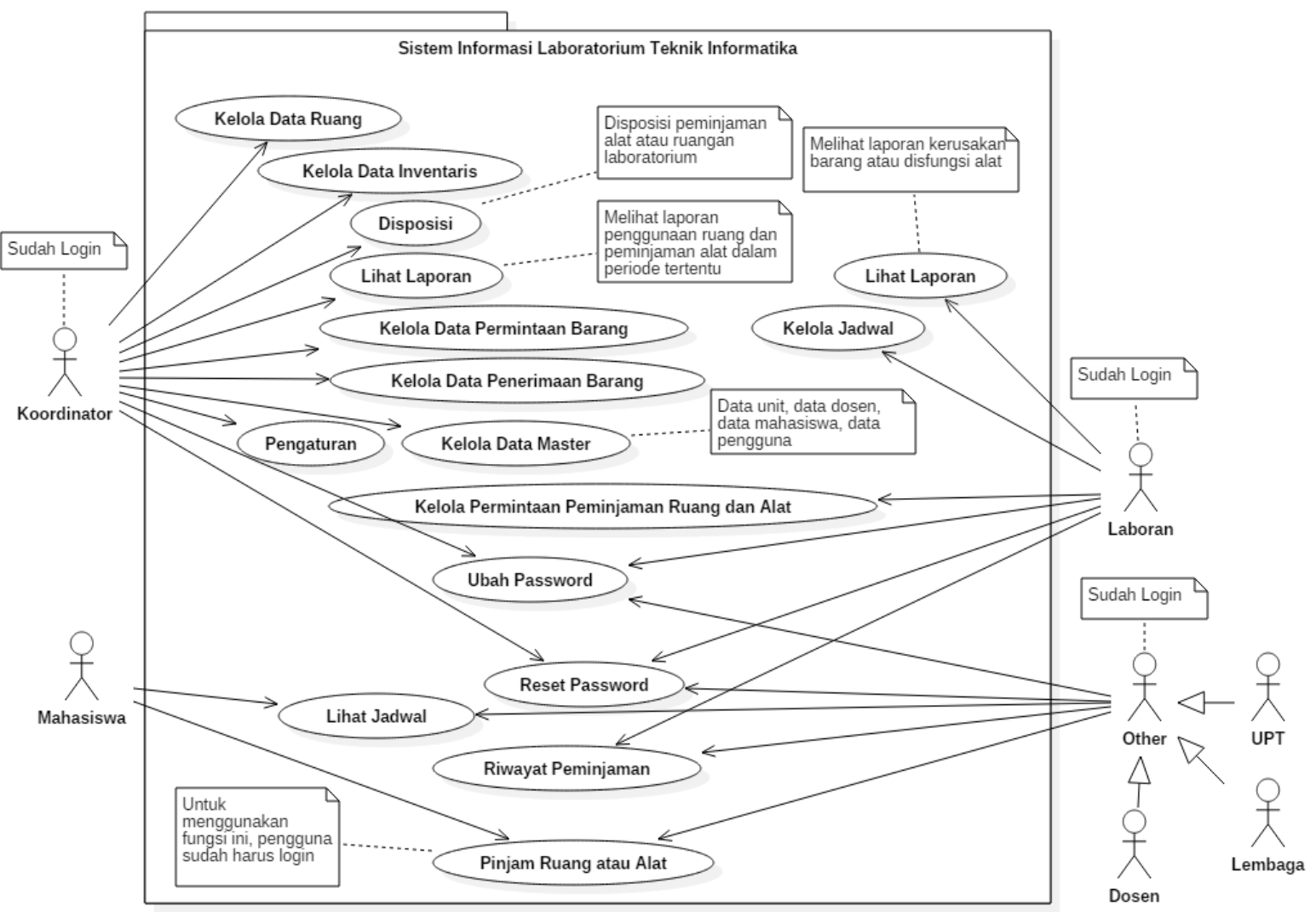

Gambar 3. Use Case Diagram Sistem Informasi Laboratorium 


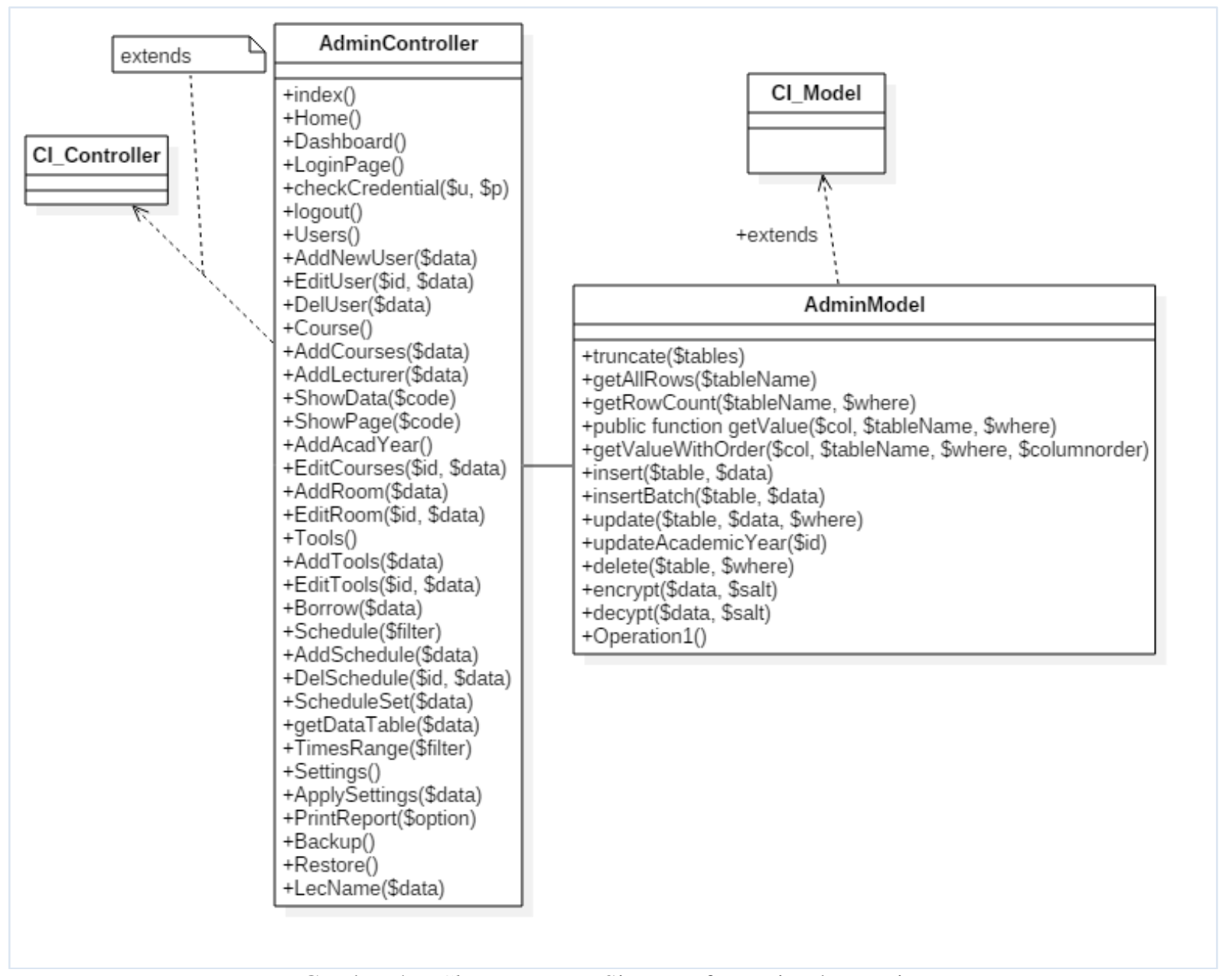

Gambar 4. Class Diagram Sistem Informasi Laboratoriu

Setelah perancangan basis data dan pembuatan use case diagram, selanjutnya dilakukan breakdown ke proses-proses yang lebih spesifik yaitu dengan memodelkan activity diagram, sequence diagram, dan class diagram (lihat pada Gambar 4). Setelah pemodelan setelesai, selanjutnya dilakukan perancangan antarmuka (user-interface) yang relevan dengan kebutuhan sistem. Kesalahan dalam perancangan dapat menimbulkan hambatan, sebaliknya bila perancangan yang telah dilakukan sangat baik, maka akan membuat pengembangan, peningkatan fungsi, dan pemeliharaan sistem menjadi lebih mudah dan efisien [15]

Implementasi Sistem (atau biasa disebut Pembuatan Sistem, Pembangunan Sistem): Setelah perancangan selesai, proses dilanjutkan dengan memulai pembuatan sistem, meliputi: Pembuatan basis data dan tabel-tabel (dari data yang telah didapatkan dari Program Studi D IV Teknik Inforrmatika Politeknik Harapan Bersama Tegal); Menghubungkan sistem dengan basis data (konfigurasi koneksi); Menerapkan template pada framework Codeigniter; Melakukan pengkodingan untuk membuat model (class yang digunakan untuk manipulasi data pada database), view (tampilan aplikasi, client-side programming), dan contoller (class yang digunakan untuk memproses request yang datang dari user melewati browser dan URL tertentu, atau sever-side programming).

Pengujian Sistem: Setelah pembuatan sistem selesai, tahapan selanjutnya adalah tahap pengujian. Pengujian sistem pada penelitian ini dilakukan menggunakan metode Blackbox Testing untuk memastikan apakah sistem yang telah dibangun dapat berjalan dengan baik (apakah terdapat error atau tidak), dan apakah semua proses atau fungsionalitas sistem dapat berjalan dengan baik dan sesuai dengan yang diharapkan [16]. Jika masih ditemukan error atau ketidaksesuaian fungsionalitas, maka perlu dilakukan perbaikan pada tahapan tertentu, biasanya pada tahapan implementasi atau bahkan tahapan perancangan jika ditemukan banyak ketidaksesuain fungsionalitas dengan kebutuhan pengguna. Pengujian blackbox (hanya sebagian pengujian) seperti ditunjukkan pada Tabel 3 dan 4. 
Tabel 3. Pengujian Blackbox (Fungsi Login)

\begin{tabular}{|c|c|c|c|c|}
\hline No & Aktivitas Pengujian & Hasil yang diharapkan & Hasil Pengujian & Status Uji \\
\hline 1 & Request halaman login & Muncul form login & $\begin{array}{l}\text { Sistem menampilkan } \\
\text { halaman berisi form } \\
\text { pengguna }\end{array}$ & $\begin{array}{l}{[\sqrt{ }] \text { Valid }} \\
{[] \text { Tidak Valid }}\end{array}$ \\
\hline 2 & $\begin{array}{l}\text { Klik Tombol "Masuk" } \\
\text { Kondisi: kotak isian } \\
\text { username dan/ atau } \\
\text { password belum diisi }\end{array}$ & $\begin{array}{l}\text { Muncul dialog } \\
\text { peringatan dengan } \\
\text { pesan kesalahan }\end{array}$ & $\begin{array}{l}\text { Sistem menampilkan } \\
\text { dialog peringatan berisi } \\
\text { informasi pesan } \\
\text { kesalahan. }\end{array}$ & $\begin{array}{l}{[\sqrt{ }] \text { Valid }} \\
{[] \text { Tidak Valid }}\end{array}$ \\
\hline 3 & $\begin{array}{l}\text { Klik Tombol "Masuk" } \\
\text { Kondisi: kotak isian } \\
\text { username dan password } \\
\text { telah diisi, namun } \\
\text { username dan/ atau } \\
\text { password yang diisikan } \\
\text { salah. }\end{array}$ & $\begin{array}{l}\text { Muncul dialog } \\
\text { peringatan dengan } \\
\text { pesan kesalahan }\end{array}$ & $\begin{array}{l}\text { Sistem menampilkan } \\
\text { dialog peringatan berisi } \\
\text { informasi pesan } \\
\text { kesalahan (username/ } \\
\text { password salah) }\end{array}$ & $\begin{array}{l}{[\sqrt{ }] \text { Valid }} \\
{[\text { ] Tidak Valid }}\end{array}$ \\
\hline 4 & $\begin{array}{l}\text { Klik tombol "Masuk" } \\
\text { Kondisi: kotak isian } \\
\text { username dan password } \\
\text { telah diisi, dan keduanya } \\
\text { bernilai benar. }\end{array}$ & $\begin{array}{l}\text { Masuk ke halaman } \\
\text { utama sistem informasi } \\
\text { sesuai level pengguna. }\end{array}$ & $\begin{array}{l}\text { Sistem menampilkan } \\
\text { halaman uatama sistem } \\
\text { informasi laboratorium } \\
\text { (dengan fiturr/menu) } \\
\text { sesuai level pengguna. }\end{array}$ & $\begin{array}{l}{[\sqrt{ }] \text { Valid }} \\
{[\text { ] Tidak Valid }}\end{array}$ \\
\hline
\end{tabular}

Tabel 4. Pengujian Blackbox (Lihat Jadwal)

\begin{tabular}{|c|c|c|c|c|}
\hline No & Aktivitas/Butir Pengujian & Hasil yang diharapkan & Hasil Pengujian & Status Uji \\
\hline 1 & Klik menu "Lihat Jadwal" & $\begin{array}{l}\text { Muncul halaman berisi } \\
\text { form filter jadwal } \\
\text { dengan } 3 \text { dropdown } \\
\text { (bulan, tahun, dan } \\
\text { ruang) dan } 1 \text { tombol } \\
\text { cari. }\end{array}$ & $\begin{array}{l}\text { Sistem menampilkan } \\
\text { halaman form filter } \\
\text { jadwal dengan sempurna. }\end{array}$ & $\begin{array}{l}{[\sqrt{ }] \text { Valid }} \\
{[\text { ] Tidak Valid }}\end{array}$ \\
\hline 2 & Automasi Filtering 1 & $\begin{array}{l}\text { Pada saat form filter } \\
\text { jadwal muncul, } \\
\text { dropdown bulan secara } \\
\text { otomatis akan terpilih } \\
\text { bulan saat ini (current } \\
\text { month). }\end{array}$ & $\begin{array}{l}\text { Pada saat form filter } \\
\text { selesai diload, sistem } \\
\text { otomatis memilih } \\
\text { option/item pada } \\
\text { dropdown bulan sesuai } \\
\text { bulan saat ini. }\end{array}$ & $\begin{array}{l}{[\sqrt{ }] \text { Valid }} \\
{[\text { ] Tidak Valid }}\end{array}$ \\
\hline 3 & Automasi Filtering 2 & $\begin{array}{l}\text { Pada saat form filter } \\
\text { jadwal muncul, } \\
\text { dropdown tahun secara } \\
\text { otomatis akan terpilih } \\
\text { tahun saat ini (current } \\
\text { year). }\end{array}$ & $\begin{array}{l}\text { Pada saat form filter } \\
\text { selesai diload, sistem } \\
\text { otomatis memilih } \\
\text { option/item pada } \\
\text { dropdown tahun sesuai } \\
\text { tahun saat ini. }\end{array}$ & $\begin{array}{l}{[\sqrt{ }] \text { Valid }} \\
{[\text { ] Tidak Valid }}\end{array}$ \\
\hline 4 & Automasi Filtering 3 & $\begin{array}{l}\text { Pada saat form filter } \\
\text { jadwal muncul, } \\
\text { dropdown ruang secara } \\
\text { otomatis akan terbuka } \\
\text { dan menampilkan } \\
\text { pilihan yang ada } \\
\text { (setelah } 1 \text { detik). }\end{array}$ & $\begin{array}{l}\text { Pada saat form filter } \\
\text { selesai diload, sistem } \\
\text { secara otomastis (setelah } \\
1 \text { detik) membuka } \\
\text { dropdown ruang dan } \\
\text { menampilkan pilihan } \\
\text { opsinya. }\end{array}$ & $\begin{array}{l}{[\sqrt{ }] \text { Valid }} \\
{[\text { ] Tidak Valid }}\end{array}$ \\
\hline 5 & $\begin{array}{l}\text { Klik tombol "Lihat" } \\
\text { Kondisi: pengguna belum } \\
\text { memilih opsi pada } \\
\text { dropdown } \\
\text { bulan/tahun/ruang. }\end{array}$ & $\begin{array}{l}\text { Muncul dialog } \\
\text { peringatan berisi pesan } \\
\text { kesalahan pengguna. }\end{array}$ & $\begin{array}{l}\text { Sistem menampilkan } \\
\text { dialog berisi pesan } \\
\text { kesalahan pengguna. }\end{array}$ & $\begin{array}{l}{[\sqrt{ }] \text { Valid }} \\
{[\text { ] Tidak Valid }}\end{array}$ \\
\hline
\end{tabular}


Klik tombol "Lihat"

Kondisi: pengguna sudan memilih opsi pada dropdown bulan, tahun, dan ruang.
Muncul daftar/list

jadwal penggunaan dan ketersediaan ruang

laboratorium sesuai filter yang diterapkan.
Sistem menampilkan jadwal sesuai filter yang diterapkan.
[ $]$ Valid

[ ] Tidak Valid

Jika dalam pengujian ditemukan status uji tidak valid, maka akan dilakukan perbaikan pada pengkodingan

Evaluasi Sistem: Setelah pengujian sistem selesai, selanjutnya dilakukan evaluasi meliputi: koreksi dari berbagai error yang tidak ditemukan pada tahap-tahap pengujian blackbox. Evaluasi pertama, beberapa saat (tidak terlalu lama) setelah implementasi dan pengujian sistem, tujuannya adalah jika perlukan adanya perbaikan, maka peneliti dapat menganalisa dengan cepat terhadap perbaikan yang perlu dilakukan; Evaluasi kedua, setelah tahapan pertama sistem berjalan, tujuannya untuk meyakinkan apakah sistem tersebut sudah berjalan sesuai dengan tujuan awal atau masih ada penyempurnaan yang harus dilakukan; Evaluasi ketiga, menguji sisi kegunaan, sampai sejauh mana aplikasi dapat bermanfaat bagi pengguna (evaluasi tahap-3 ini belum dilakukan pada penelitian ini, karena sementara kegiatan akademik dilaksanakan secara daring, dampak dari pandemi COVID-19).

\section{HASIL DAN PEMBAHASAN}

Hasil penelitian ini berupa sebuah sistem informasi laboratorium yang dapat digunakan untuk membantu mempermudah manajemen operasional laboratorium, diantaranya fungsi manajemen data master (lihat Gambar 5) yang meliputi: data ruang; data akademik (data kurikulum, mata kuliah, dosen pengampu, dan tahun akademik); data alat/barang; data SOP; data pengguna; dan data pogram studi, penjadwalan penggunaan ruang laboratorium (lihat pada Gamba 6, 7, dan 8), disposisi peminjaman ruang dan alat, manajemen permintaan alat praktikum, informasi ketersediaan ruang dan alat, sistem pelaporan, pengaturan sistem (lihat Gambar 9), dan sistem inventarisasi alat.
Penggunaan sistem dimulai dengan koordinator melakukan entri data master dan mengatur waktu operasional penggunaan ruang laboratorium, kurikulum aktif (untuk masing-masing Program Studi, karena laboratium digunakan oleh banyak Program Studi, atau shared-lab), tahun akademik aktif. Setelah data master siap dan pengaturan awal telah ditentukan, selanjutnya dilanjutkan dengan mengatur jadwal penggunaan ruang laboratorium. Pengaturan jadwal ini hanya perlu meng-entri data jadwal 1 (satu) minggu, dan secara otomatis sistem akan menjadwalkan penggunaan ruang laboratorium selama 1 (satu) semester. Setelah penjadwalan penggunaan ruang dilakukan, selanjutnya pengguna dapat melihat informasi penggunaan dan ketersediaan ruang/alat. Jika pengguna (dalam hal ini dosen dan unit/lembaga) ingin meminjam ruang/alat, maka pengguna tinggal mengisi form dan memilih waktu yang diinginkan (lihat Gambar 10), namun tetap harus menunggu disposisi dari koordinator Laboratorium.

Dalam aplikasi atau sistem hasil penelitian ini, data primer atau data master yang digunakan adalah data yang didapatkan dari berbagai bidang di Politeknik Harapan Bersama, sehingga penyimpanan data masih terpisah dari server sistem lain yang seharusnya dapat saling terintegrasi, seperti sistem kepegawaian, sistem Biro Administrasi Umum serta sistem Informasi Akademik. Hal ini berdampak pada suatu kondisi, yaitu jika terjadi perubahan pada data master institusi, maka juga perlu dilakukan update data pada sistem ini. 


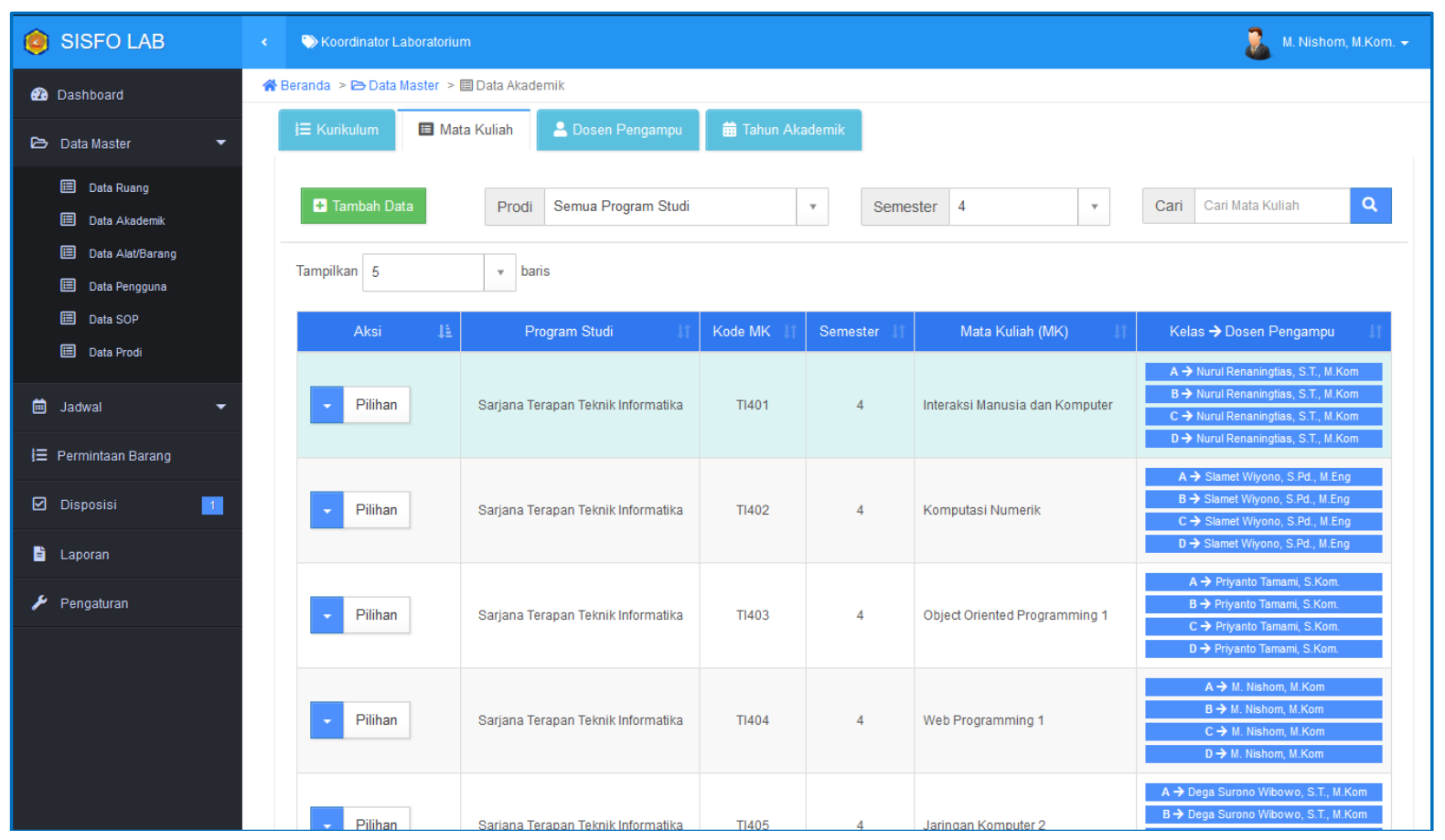

Gambar 5. Halaman Data Master

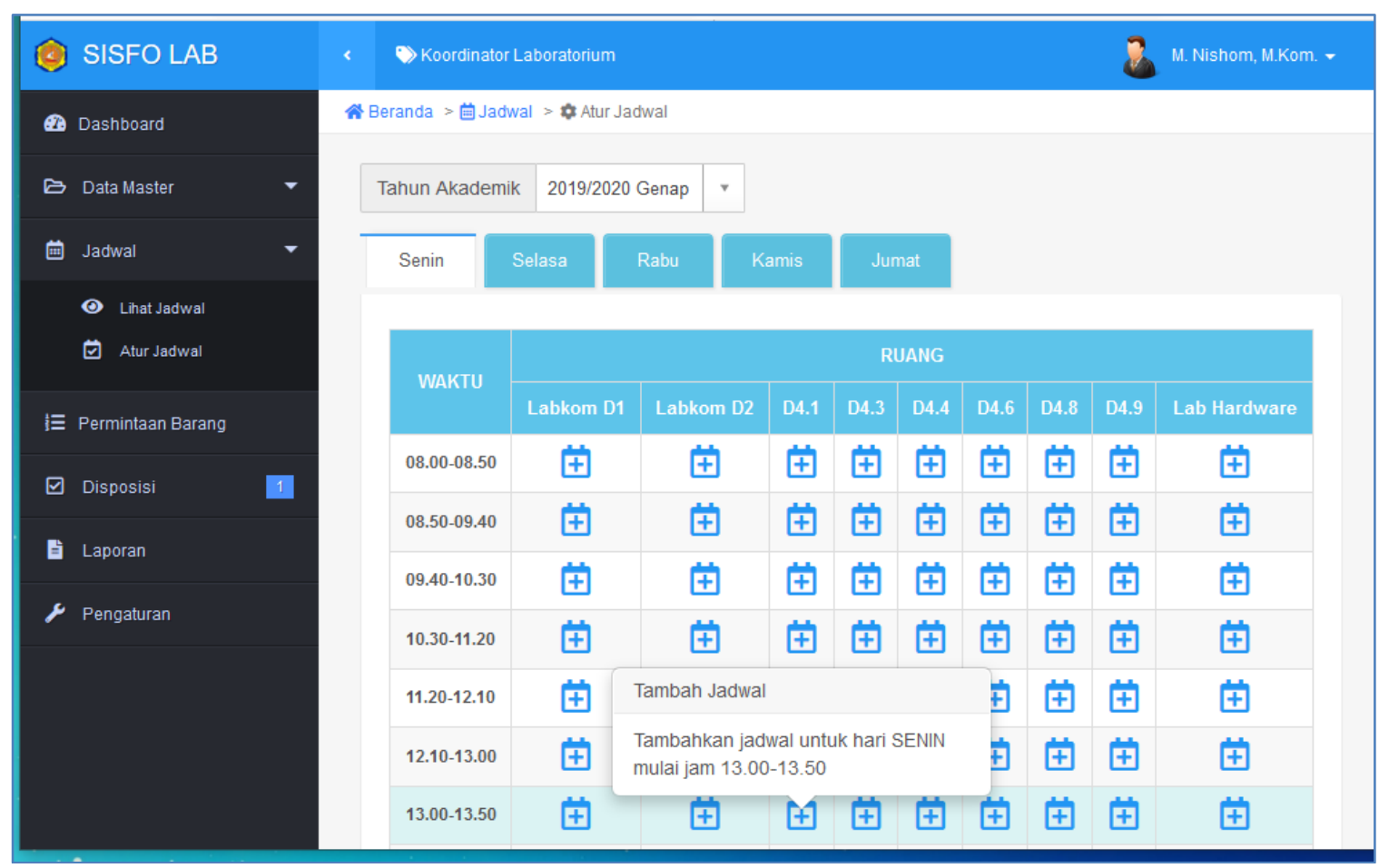

Gambar 6. Halaman Atur Jadwal Penggunaan Ruang 


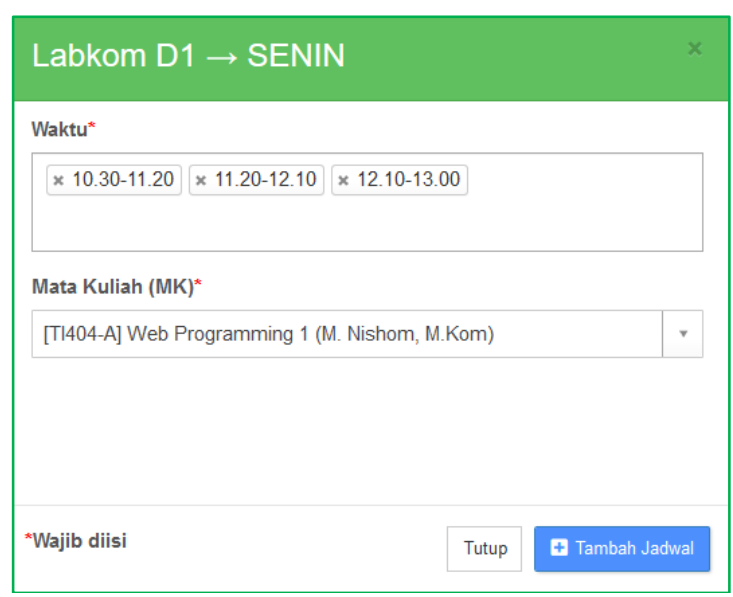

Gambar 7. Forrm Penambahan Jadwal Penggunaan Ruang Laboratorium

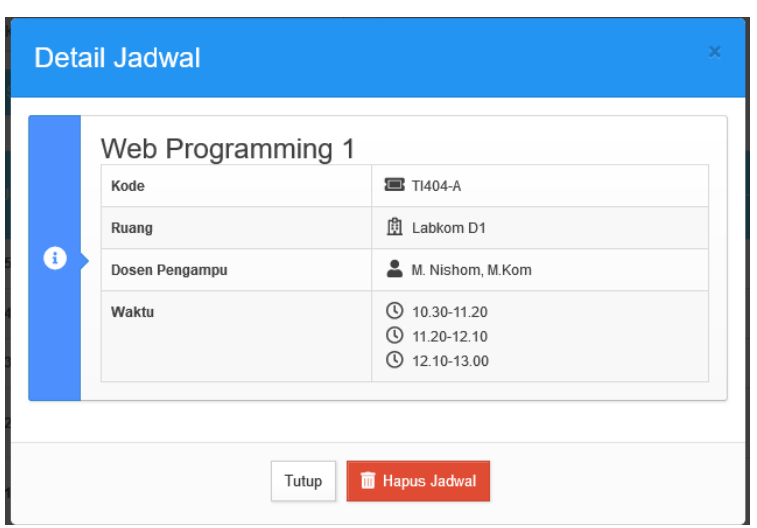

Gambar 8. Lihat Detail Jadwal Penggunaan Ruang Laboratorium

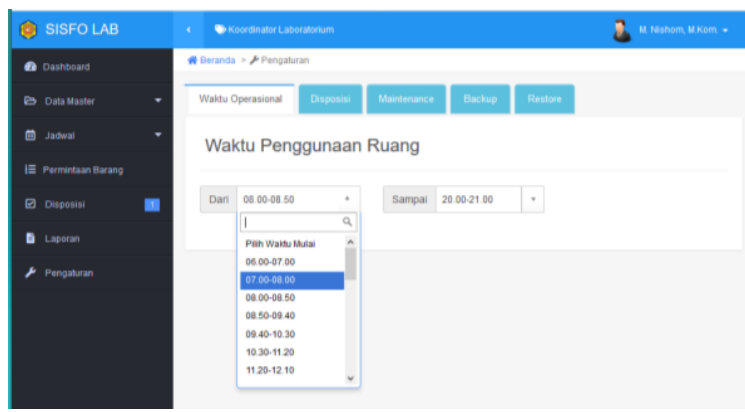

Gambar 9. Halaman Pengaturan Sistem

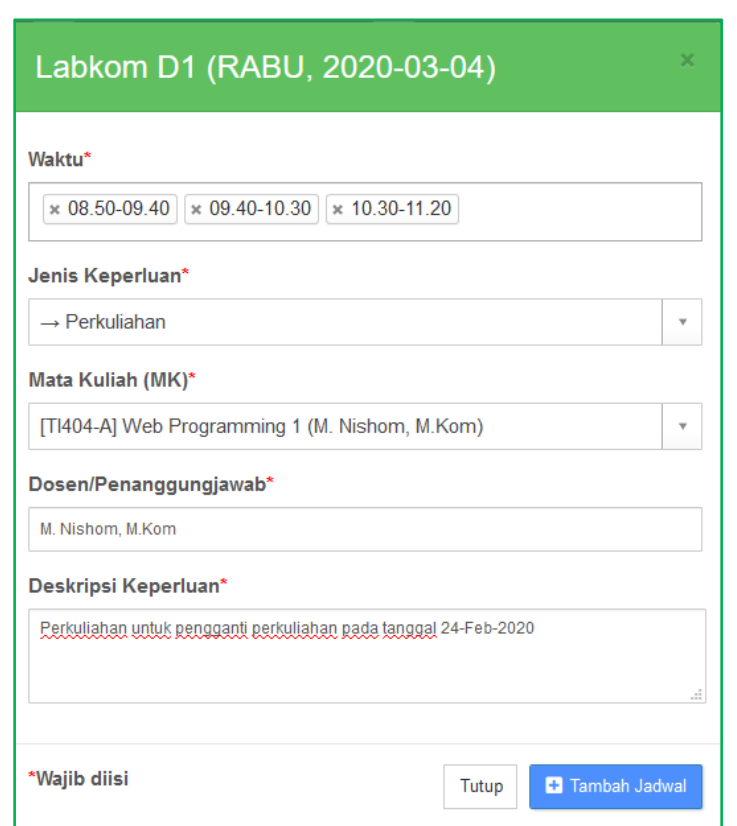

Gambar 10. Form Peminjaman Ruang Laboratorium

\section{KESIMPULAN}

Berdasarkan hasil kegiatan penelitian yang telah dilaksanakan, maka dapat diambil simpulan sebagai berikut: Aplikasi hasil penelitian dapat digunakan sebagai media untuk informasi ketersediaan ruang dan alat, peminjaman ruat dan alat, dan memudahkan pengelola laboratorium dalam melakukan pengelolaan data laboratorium; Hasil pengujian sistem menggunakan metode blackbox menunjukkan bahwa semua fungsionalitas sistem telah berjalan dengan baik (valid), sehingga sistem telah siap untuk digunakan dan diterapkan di Program Studi D IV Teknik Informatika. Saran untuk pengembangan sistem berikutnya dapat diimplementasikan ke dalam aplikasi mobile agar lebih memudahkan pengguna dalam melakukan peminjaman maupun melihat informasi laboratorium, dan memudahkan pengelola laboratorium dalam mengelola data dan informasi laboratorium.

\section{UCAPAN TERIMA KASIH}

Penulis mengucapkan terimakasih kepada program studi, unit pelaksana teknis, dan lembaga sebagai penyedia data pada masyarakat ini, dan kepada Politeknik Harapan Bersama yang telah memberikan pendanaan pada pelaksanaan penelitian ini.

\section{DAFTAR PUSTAKA}

1. E. Y. Anggraeni, 2017, Pengantar Sistem Informasi. Yogyakarta: Penerbit Andi.

2. G. Piccoli and F. Pigni, 2018, Information Systems for Managers: With Cases, 4th ed. Burlington: Prospect Press.

3. Pespmc1.vub.ac.be, Information System.

4. Businessdictionary.com, What is information System?. 
5. R. Stair and G. Reynolds, 2017, Fundamentals of Information Systems, 9th ed. Boston: Cengage Learning.

6. W. Suh, Web Engineering: 2005, Principles and Techniques. Hershey: Idea Group Inc (IGI).

7. I. G. N. W. Arsa, 2018, Analisis Dan Perancangan Sistem Informasi Manajemen Laboratorium STMIK STIKOM Bali Berbasis Web, J. Sist. dan Inform., vol. 10, no. 1, pp. 8798.

8. W. Yoanna, A. Handojo, and R. Intan, 2005, Aplikasi Peminjaman Ruangan, Kendaraan, Peralatan Dan Penyampaian Keluhan Serta Analisis Ketersediaan Barang Dan Kinerja Pelayanan Pada Uppk Universitas Kristen Petra," J. Inform., vol. 6, no. 2, pp. 65-70.

9. D. Pamungkas, A. Sanjaya, and F. A. Sholih, 2017, Sistem Informasi Laboratorium Komputer di Universitas Nusantara PGRI Kediri, SNATIKA, vol. 4, pp. 37-42.

10. M. Abdurahman, 2016, Sistem Informasi Jadwal Perkuliahan Berbasis Web Mobile Pada Politeknik Sains dan Teknologi Wiratama
Maluku Utara, Indones. J. Netw. Secur., vol. 5, no. 2, pp. 49-56.

11. G. T. Sanjaya, 2015, Rancang Bangun Aplikasi Penjadwalan Kuliah STMIK AUB Surakarta Berbasis Web, J. Ilm. GO INFOTECH, vol. 21, no. 1, pp. 37-42.

12. H. W. Luthfi and B. K. Riasti, 2011, Sistem Informasi Maintenance Dan Inventaris Laboratorium Pada SMK Negeri 1 Rembang Berbasis Web, J. Speed - Sentra Penelit. Eng. dan Edukasi, vol. 3, no. 3, pp. 69-77.

13. R. McLeod and E. Jordan, 2011, Systems Development: A Project Management Approach. Hoboken: Wiley.

14. Sugiyono, 2019, Metode Penelitian Kuantitatif, Kualitatif Dan R\&D, 1st ed. Bandung: Alfabeta.

15. K. E. Kendall, 2010, Analisis dan Perancangan Sistem, 5th ed. Jakarta: PT Indeks.

16. G. Jerry, T. H., and Y. Wu, 2003, Testing and Quality Assurance for Component-based Software. Norwood, Massachusetts: Artech House. 